\title{
Application evaluation of DCE-MRI combined with quantitative analysis of DWI for the diagnosis of prostate cancer
}

\author{
XIANG-ZHENG MA ${ }^{1}$, KUN LV ${ }^{2}$, JIAN-LIANG SHENG ${ }^{1}$, YING-XING YU ${ }^{1}$, \\ PEI-PEI PANG ${ }^{3}$, MAO-SHENG XU ${ }^{1}$ and SHI-WEI WANG ${ }^{1}$ \\ ${ }^{1}$ Department of Radiology, The First Affiliated Hospital of Zhejiang Chinese Medical University; \\ ${ }^{2}$ The First Clinical Medical College, Zhejiang Chinese Medical University, Hangzhou, Zhejiang 310006; \\ ${ }^{3}$ Department of Life Sciences, GE Healthcare, Shanghai 201203, P.R. China
}

Received March 21, 2018; Accepted November 29, 2018

DOI: $10.3892 / 01.2019 .9988$

\begin{abstract}
The present study aimed to investigate the value of dynamic contrast-enhanced magnetic resonance imaging (DCE-MRI) combined with quantitative analysis of diffusion weighted imaging (DWI) for the diagnosis of prostate cancer (PCa). A total of 81 patients with prostatic diseases, including $\mathrm{PCa}(\mathrm{n}=44)$ and benign prostatic hyperplasia $(\mathrm{BPH}$, $\mathrm{n}=37$ ), were imaged with T1 weighted imaging (T1WI), T2 weighted imaging (T2WI), DWI and DCE-MRI. The blood vessel permeability parameters volume transfer rate constant $\left(\mathrm{K}^{\text {trans }}\right)$, back flow rate constant $\left(\mathrm{K}_{\mathrm{ep}}\right)$, extravascular extracellular space volume fraction $\left(\mathrm{V}_{\mathrm{e}}\right)$, plasma volume fraction $\left(\mathrm{V}_{\mathrm{p}}\right)$ and apparent diffusion coefficient (ADC) were measured, and compared between the two groups. The efficiency of these tools for the diagnosis of PCa was analyzed by receiver operating characteristic curve analysis. The efficiency of ADC combined with blood vessel permeability parameters in the diagnosis of PCa was analyzed by logistic regression. The correlation between these parameters and the Gleason score was evaluated by Spearman correlation analysis in the $\mathrm{PCa}$ group. The results demonstrated that, compared with the $\mathrm{BPH}$ group, $\mathrm{K}^{\text {trans }}, \mathrm{K}_{\mathrm{ep}}, \mathrm{V}_{\mathrm{e}}$ and $\mathrm{V}_{\mathrm{p}}$ were higher, and $\mathrm{ADC}$ was lower in the PCa group $(\mathrm{P}<0.05)$. The combination of $\mathrm{K}_{\mathrm{ep}}$ and $\mathrm{ADC}$ offered the highest diagnosis efficiency [area under the curve (AUC=0.939)]. However, the combination of three parameters did not significantly improve the diagnostic efficiency. A subtle improvement in diagnostic efficiency was observed when four parameters $\left(\mathrm{K}^{\text {trans }}+\mathrm{K}_{\mathrm{ep}}+\mathrm{V}_{\mathrm{e}}+\mathrm{ADC}\right)$ were combined (AUC $=0.940$ ), which was significantly higher than with one parameter. The ADC value of the PCa group
\end{abstract}

Correspondence to: Professor Shi-Wei Wang, Department of Radiology, The First Affiliated Hospital of Zhejiang Chinese Medical University, 54 Youdian Road, Shangcheng, Hangzhou, Zhejiang 310006, P.R. China

E-mail: 2474721554@qq.com

Key words: prostate cancer, dynamic contrast-enhanced magnetic resonance imaging, diffusion weighted imaging, Gleason score was negatively correlated with the primary Gleason pattern, secondary Gleason pattern and the total Gleason score in PCa $(\mathrm{r}=-0.665,-0.456$ and -0.714 , respectively; $\mathrm{P}<0.001)$. The $\mathrm{V}_{\mathrm{p}}$ in the PCa group was slightly negatively correlated with the primary Gleason pattern of $\mathrm{PCa}(\mathrm{r}=-0.385$; $\mathrm{P}<0.05)$; however, no significant correlation was found with secondary Gleason pattern and the total Gleason score. The present study revealed that the combination of DCE-MRI quantitative analysis and DWI was efficient for PCa diagnosis. This may be because DCE-MRI and DWI can noninvasively detect water motility in tumor tissues and alterations in permeability during tumor neovascularization. The present study demonstrated that $\mathrm{K}_{\mathrm{ep}}$ and ADC values may be used as predictive parameters for $\mathrm{PCa}$ diagnosis, which may help differentiate benign from malignant prostate lesions.

\section{Introduction}

Prostate cancer ( $\mathrm{PCa}$ ) is the most common type of cancer in elderly men, the incidence of which increases annually $(1,2)$. The diagnosis of PCa is easily delayed or missed due to the absence of symptoms, particularly in the early stage of the disease. In addition, some symptoms of PCa are similar to those of other diseases, including benign prostatic hyperplasia (BPH), prostatitis, urinary tract infection, cystitis and urethral stricture. Magnetic resonance imaging (MRI) is the best imaging method for PCa diagnosis, allowing unique anatomic assessment of the prostate and the best soft tissue resolution. MRI is used in all stages of PCa, from initial detection to treatment planning and follow-up. However, the traditional MRI method lacks specificity and the diagnostic accuracy needs to be improved. To circumvent this issue, multi-modal MRI has been used to assess lesion perfusion and diffusion characteristics of water molecules, allowing better analysis of the tumor metabolic states. This has crucial implications in the diagnosis, grading and prognostic prediction of PCa (3). Dynamic contrast-enhanced MRI (DCE-MRI) is an imaging method that analyzes tumor angiogenesis by observing the diffusion of contrast agents into the extravascular space over time. In comparison with BPH, PCa acquires novel vasculature through angiogenesis, develops metastasis and establishes tumors of enhanced permeability. In the present study, the 
parameters volume transfer rate constant $\left(\mathrm{K}^{\text {trans }}\right)$, back flow rate constant $\left(\mathrm{K}_{\mathrm{ep}}\right)$, extravascular extracellular space volume fraction $\left(\mathrm{V}_{\mathrm{e}}\right)$ and plasma volume fraction $\left(\mathrm{V}_{\mathrm{p}}\right)$ of each lesion were measured quantitatively by DCE-MRI, which indirectly measures quantity and permeability of new blood vessels. These measurements serve to evaluate hemodynamic and metabolic characteristics of the lesions (4). Although DCE-MRI provides quantitative analysis of tumor vascular permeability, the accuracy of some parameters is still debatable.

Diffusion weighted imaging (DWI) reflects the Brownian movement of water in living tissues by imaging diffusion characteristics. It is widely used for the diagnosis of central nervous system diseases (5). Recently, this method has also been applied to the diagnosis of systemic tumors, including breast, hepatic and renal tumors (6). The main evaluation parameter of DWI is the apparent diffusion coefficient (ADC), which reflects the diffusion speed and range of motion. ADC is associated with tumor growth and invasion, and lower ADC values represent a limited degree of diffusion. DWI can also be used for quantitative analysis of the structural and cellular characteristics of $\mathrm{PCa}$; however, the results can easily be influenced by interference of magnetic artifacts (6). Therefore, the present study aimed to investigate the value of DCE-MRI combined with DWI quantitative analysis in the diagnosis of PCa. The study also evaluated the correlation between vascular permeability parameters and ADC, and Gleason grading and $\mathrm{PCa}$ scoring, which provides imaging evidence for the biological invasion and clinical identification of PCa.

\section{Materials and methods}

Subjects. A total of 81 patients with increased prostate-specific antigen (PSA) and clinically suspected PCa were recruited from The First Affiliated Hospital of Zhejiang Chinese Medical University (Zhejiang, China) between October 2014 and January 2016. Inclusion criteria were as follows: i) No MRI scanning contraindications; ii) no endocrine therapy, radiotherapy or other non-surgical treatment prior to MRI scanning; and iii) no prostate biopsy within 1 month of MRI. The diagnosis of 44 patients with PCa (age, 59-85 years; mean, $74 \pm 7$ years) and 37 patients with BPH (age 52-96 years, mean, $72 \pm 11$ years) was confirmed by biopsy or surgical pathology during the first week of selection, and tumors were assessed by $\mathrm{T} 1$ weighted imaging (T1WI), T2 weighted imaging (T2WI), DWI and DCE-MRI. The institutional review board of The First Affiliated Hospital of Zhejiang Chinese Medical University (Zhejiang, China) approved this retrospective study and waived informed consent.

MRI acquisition. Imaging was conducted on a 3.0 Tesla MR scanner (Siemens Healthcare GmbH, Erlangen, Germany), equipped with a 16-channel body phased array surface coil. patients were fasted and deprived of water $4 \mathrm{~h}$ prior to MRI, and imaging was conducted following defecation and urination in order to reduce interference due do intestinal tract contents and bladder motility artifacts. During imaging, patients were placed in the supine position with the foot at the advanced position and the scanning center located $2 \mathrm{~cm}$ above the pubic symphysis. All patients wore noise-cancelling headsets. General scans used short time inversion, fat suppression sequences with transverse, sagittal and coronal T2WI as follows: Repetition time $(\mathrm{TR})=4,000 \mathrm{msec}$, echo time $(\mathrm{TE})=96 \mathrm{msec}$, thickness $=3 \mathrm{~mm}$, field-of-view $(\mathrm{FOV})=240 \times 240 \mathrm{~mm}$, number of excitations $(\mathrm{NEX})=2$, matrix $=320 \times 320$. DWI scans were performed using a single shot echo sequence as follows: $\mathrm{TR}=4,500 \mathrm{msec}, \mathrm{TE}=93 \mathrm{msec}$, thickness $=4 \mathrm{~mm}$, $\mathrm{FOV}=260 \times 221 \mathrm{~mm}, \mathrm{NEX}=4$, matrix $=160 \times 120$. B values of 50 and $700 \mathrm{~s} / \mathrm{mm}^{2}$ were selected, and ADC was reconstructed automatically after the scan. DCE-MRI used three-dimensional volumetric interpolated body scanning sequence of axial T1WI. Galodinium-diethylenetriamine penta-acetic acid (Gd-DTPA) contrast (Hokuriku Seiyaku Co., Ltd, Katsuyama, Japan) was administered intravenously via the median cubital vein at a dose of $0.1 \mathrm{mmol} / \mathrm{kg}$ and a rate of $2 \mathrm{ml} / \mathrm{sec}$. After injection, the solution was flushed with $10 \mathrm{ml} 0.9 \%$ sodium chloride. The protocol scanning parameters of DCE-MRI were as follows: $\mathrm{TR}=5.80 \mathrm{msec}, \mathrm{TE}=2.17 \mathrm{msec}$, thickness $=3.60 \mathrm{~mm}$, $\mathrm{FOV}=260 \times 211 \mathrm{~mm}$, matrix $=352 \times 352, \mathrm{NEX}=1$ and scanning repetitions $=15$.

Gleason grading and scoring method. Pathological samples were obtained from 15 patients with PCa who underwent surgical tumor biopsy and 29 patients with $\mathrm{PCa}$ who underwent $6+4$ prostate biopsies guided by transrectal ultrasonography (TRUS). Briefly, after 6 puncture points, 2 points were added to each side of the peripheral area and then 1-2 needles were added to the suspicious area. Tissue was extracted by puncture, fixed in $10 \%$ neutral-buffered-formalin for $24 \mathrm{~h}$ at room temperature and paraffin-embedded. Sections ( $4 \mu \mathrm{m}$-thick) were then stained with hematoxylin and eosin for $1 \mathrm{~h}$ at room temperature. Subsequently, histopathological analysis was performed under a light microscope (magnification, x100). The sections were evaluated for Gleason grading and scoring (7). The Gleason system, introduced in 1974, is an architectural grading system that ranges from 1 (well differentiated) to 5 (poorly differentiated). The Gleason score is the sum of the primary and secondary patterns with a range of 2-10 $(8,9)$.

MRI data processing. MRI images were submitted to the Siemens syngo ${ }^{\circledR}$ MR B17 workstation. Images were assessed by two senior radiologists and a general consensus was reached for each diagnosis. Diagnostic parameters included the anatomical location, shape, maximum diameter, signal intensity of the lesion, and potential alterations in the adjacent organs or tissues. After DWI completion, an ADC map was automatically generated. By using other image sequences as references, the ADC of each lesion was measured by one radiologist, who placed the region of interest (ROI) on the ADC map. For each ROI, the center of the lesion was selected as the midpoint and the region was selected to include the whole lesion. The borders of the peripheral and central zone, root of the seminal vesicle, vessel, calcification, hemorrhage or artifacts were avoided if possible. If multiple lesions were present, only the largest was measured. Each lesion was measured three times and an average ROI value was taken as the ADC value of the lesion site. DCE-MRI quantitative analysis was performed by the same physician using hemodynamics quantitative analysis Omni-Kinetics software (version 2.1.0.R; GE Healthcare, Shanghai, China) for post processing. The multiperiod DCE-MRI sequence was imported to the software. 
The femoral artery was selected as part of the circular ROI to obtain time-concentration curves of normal blood vessels. The arterial input function curve was established as a reference, and used to calculate the vascular permeability with the Extended Tofts two-compartment model (10). Models were then used to calculate the vascular permeability parameters $\mathrm{K}^{\text {trans }}, \mathrm{K}_{\mathrm{ep}}, \mathrm{V}_{\mathrm{e}}$ and $\mathrm{V}_{\mathrm{p}}$. In the dynamic contrast enhancement of the original ROI lesions, $\mathrm{K}^{\text {trans }}, \mathrm{K}_{\mathrm{ep}}, \mathrm{V}_{\mathrm{e}}$ and $\mathrm{V}_{\mathrm{p}}$ values were automatically analyzed, and used to generate various parameters for a red/blue color map image. The placement principle of ROI was the same as the measured ADC value. Each image was analyzed three times and an average was obtained.

Statistical analysis. Statistical analyses were conducted using SPSS 22.0 software (IBM Corp., Armonk, NY, USA). Two-sample t-test was performed to statistically analyze data. Vascular permeability parameters and ADC values were normally distributed and presented as the means \pm standard deviation. MedCalc (version 15.2.2; www.medcalc.org) was used to draw receiver operating characteristic (ROC) curves of vascular permeability parameters and ADC values. The area under the curve (AUC) was calculated with the cut-off value set at the maximum Youden index. The optimal threshold and diagnostic efficiency was assessed by logistic regression, which evaluated the diagnostic efficacy of ADC combined with vascular permeability parameters in PCa. Spearman correlation analysis was used to evaluate the correlation between the vascular permeability parameters and ADC values of the tumor area, and primary and secondary Gleason pattern and total Gleason score of PCa. $\mathrm{P}<0.05$ was considered to indicate a statistically significant difference.

\section{Results}

Clinical characteristics of patients. There was no significant age difference between the two groups $(\mathrm{P}=0.400)$. Among the 44 tissue samples obtained from patients with $\mathrm{PCa}$, multiple lesions were found in 15 cases. Lesions located in the periphery were found in 30 cases, whereas lesions in the transitional zone were only observed in 10 cases. Dual involvement of the peripheral and transitional zone was observed in four cases (Fig. 1A-F). Gleason scores were defined as follows: 6 points in 12 cases, 8 points in 11 cases, 9 points in 6 cases and 16 points in 7 cases. Among 37 samples from patients with BHP, multiple nodules were reported in 21 cases and all lesions were located in the transitional zone (Fig. 2A-F).

Comparison of vascular permeability parameters and $A D C$ values between both groups. The $\mathrm{K}^{\text {trans }}, \mathrm{K}_{\mathrm{ep}}, \mathrm{V}_{\mathrm{e}}, \mathrm{V}_{\mathrm{p}}$ and ADC values of PCa patients were $(2.40 \pm 1.13) \mathrm{min}^{-1}$, $(1.90 \pm 0.72) \mathrm{min}^{-1},(0.82 \pm 0.24),(0.31 \pm 0.25)$ and $(0.93 \pm 0.43)$ $\mathrm{x} 10^{-3} \mathrm{~mm}^{2} / \mathrm{sec}$, respectively. These parameters in BPH patients were $(1.07 \pm 1.08) \mathrm{min}^{-1},(1.04 \pm 0.48) \mathrm{min}^{-1},(0.64 \pm 0.37)$, $(0.43 \pm 0.36)$ and $(1.74 \pm 0.38) \times 10^{-3} \mathrm{~mm}^{2} / \mathrm{sec}$, respectively. The parameters of $\mathrm{K}^{\text {trans }}, \mathrm{K}_{\mathrm{ep}}$ and $\mathrm{V}_{\mathrm{e}}$ in the $\mathrm{PCa}$ group were higher than in the $\mathrm{BPH}$ group $(\mathrm{P}<0.05)$. The $\mathrm{ADC}$ value in the $\mathrm{BPH}$ group was higher than in the PCa group $(\mathrm{P}<0.05$; Table I).

Use of vascular permeability parameters and ADC values for the diagnosis of PCa. The AUC values for $\mathrm{K}^{\text {trans }}, \mathrm{K}_{\mathrm{ep}}, \mathrm{V}_{\mathrm{e}}, \mathrm{V}_{\mathrm{p}}$ and ADC were 0.819, 0.831, 0.703, 0.581 and 0.914, respectively. The maximum Youden indices were 0.598, 0.547, 0.498, 0.211 and 0.706 , respectively. The sensitivity and specificity of $\mathrm{K}^{\text {trans }}, \mathrm{K}_{\mathrm{ep}}, \mathrm{V}_{\mathrm{e}}$ and ADC in the group of patients with PCa were higher $(\mathrm{P}<0.01)$ than in the group of patients with $\mathrm{BPH}$. In addition, $\mathrm{V}_{\mathrm{p}}$ had no significant value for $\mathrm{PCa}$ diagnosis $(\mathrm{P}=0.211)$ (Table II and Fig. 3A).

Use of ADC value combined with vascular permeability parameters in the diagnosis of $\mathrm{PCa}$. Logistic regression was used to evaluate the efficacy of the combination of ADC value with vascular permeability parameters in the diagnosis of PCa. When two parameters were combined, the best diagnostic efficiency was achieved when $\mathrm{K}_{\mathrm{ep}}$ and ADC were combined (AUC $=0.939$ ). However, when three parameters were combined, the diagnostic efficacy was not significantly improved. Yet, when the four parameters $\mathrm{K}^{\text {trans }}+\mathrm{K}_{\mathrm{ep}}+\mathrm{V}_{\mathrm{e}}+$ ADC were combined, the diagnostic value was increased (AUC $=0.940)$, and this efficiency was significantly higher compared with only one parameter (Tables II, III and Fig. 3B).

Correlation between vascular permeability parameters, $A D C$ values and Gleason scores in PCa. Spearman correlation analysis was used to study the correlation between vascular permeability and ADC, primary Gleason patterns, secondary Gleason patterns and total Gleason score in $\mathrm{PCa}$. The ADC values of the tumor region were negatively correlated with the primary and secondary Gleason patterns, and the total Gleason score in PCa ( $r=-0.665,-0.456$ and -0.714 , respectively; $\mathrm{P}<0.001)$. A small negative correlation was demonstrated between the primary Gleason pattern and $\mathrm{V}_{\mathrm{p}}$ of $\mathrm{PCa}(\mathrm{r}=-0.385 ; \mathrm{P}<0.05)$; however, no significant correlation was found either with the secondary Gleason pattern or with the total Gleason score. In addition, no significant correlation was detected between $\mathrm{K}^{\text {trans }}, \mathrm{K}_{\mathrm{ep}}$ and $\mathrm{V}_{\mathrm{e}}$, and the primary and secondary Gleason patterns and the total Gleason score in $\mathrm{PCa}$ (P>0.05; Table IV).

\section{Discussion}

Previous studies have demonstrated that $\mathrm{K}^{\text {trans }}$ and $\mathrm{K}_{\mathrm{ep}}$ values in the central adenocarcinoma area are higher than in the central glandular noncancerous area, suggesting that these parameters may be useful to identify both regions $(11,12)$. They also revealed that the $\mathrm{K}^{\text {trans }}, \mathrm{K}_{\mathrm{ep}}$ and $\mathrm{V}_{\mathrm{e}}$ among each area had significant differences, suggesting that DCE-MRI may aid the diagnosis of $\mathrm{PCa}$. The present study demonstrated that $\mathrm{K}^{\text {trans }}, \mathrm{K}_{\mathrm{ep}}$ and $\mathrm{V}_{\mathrm{e}}$ values between patients with $\mathrm{PCa}$ and patients with $\mathrm{BPH}$ were highly sensitive and specific, and may therefore be used in the diagnosis of $\mathrm{PCa}$. In addition, $\mathrm{V}_{\mathrm{p}}$ value did not differ between the two groups, indicating that it may not be useful for PCa diagnosis. Baur et al (13) reported that the prostate imaging reporting and data system scoring system demonstrates a good diagnostic performance for the detection of PCa when using a sum score. However, DCE-MRI does not appear to significantly improve the accuracy of diagnosis. Hoeks et al (14) suggested that, compared with single T2WI, T2WI combined with DCE-MRI does not aid the diagnosis of $\mathrm{PCa}$. This study reported that the diagnostic coincidence rate was only $66 \%$. These findings indicated that DCE-MRI 

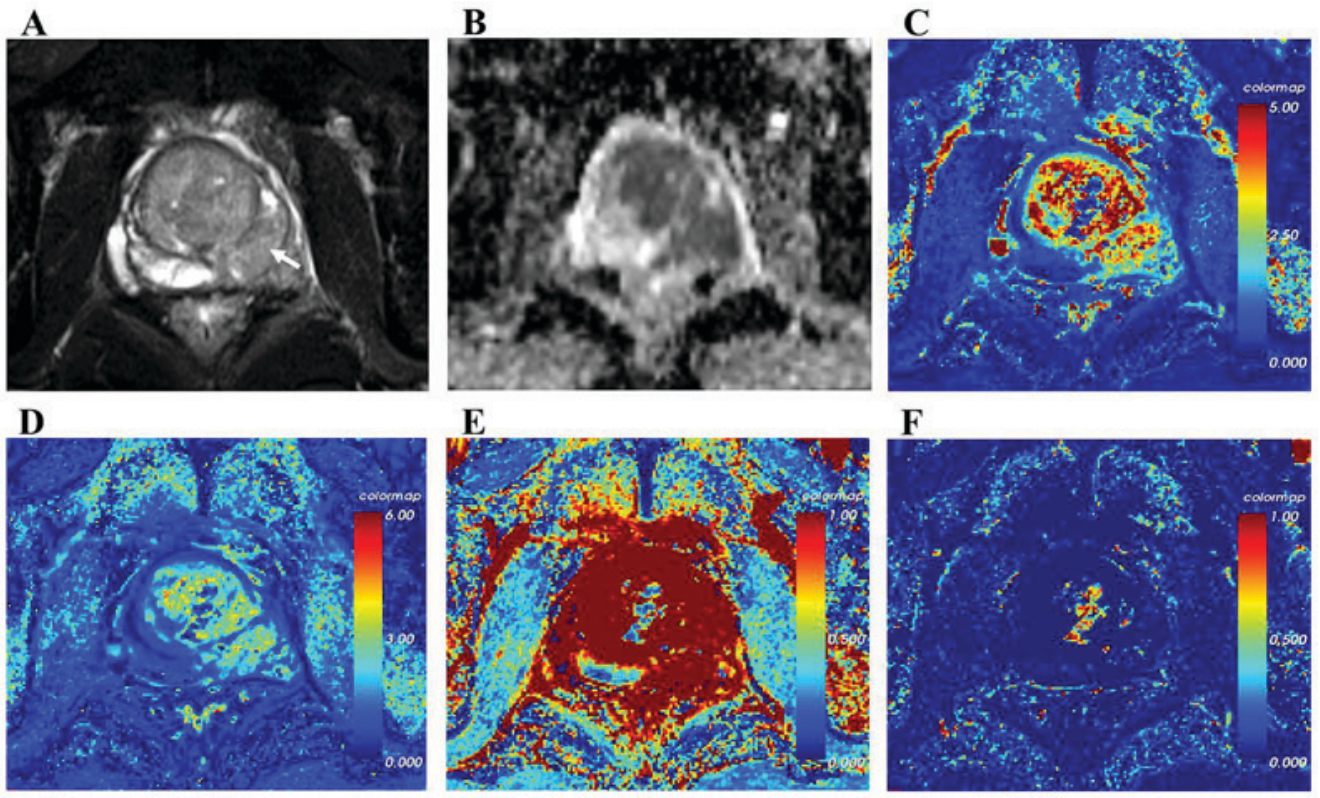

Figure 1. A 69-year-old patient with prostate cancer and dysuria 1 week after the beginning of the study (prostate-specific antigen=61.233 ng/ml). (A) On T2 weighted image, the signal of the left peripheral zone and part of the transitional zone was decreased, as indicated by the arrow. (B) ADC map shows a low signal with an ADC value of $0.790 \times 10^{-3} \mathrm{~mm}^{2} / \mathrm{sec}$. Pseudo-color maps of (C) volume transfer rate constant, (D) back flow rate constant, (E) extravascular extracellular space volume fraction and (F) plasma volume fraction showed values of $3.122 \mathrm{~min}^{-1}, 2.377 \mathrm{~min}^{-1}, 0.967$ and 0.170 , respectively. ADC, apparent diffusion coefficient.

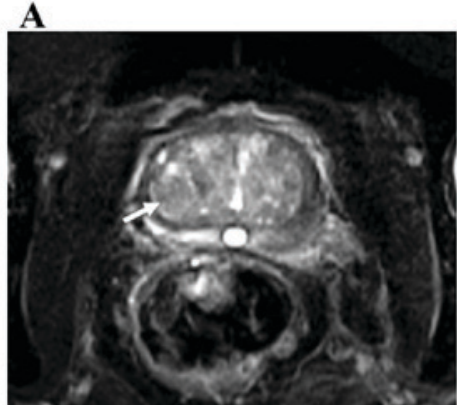

D

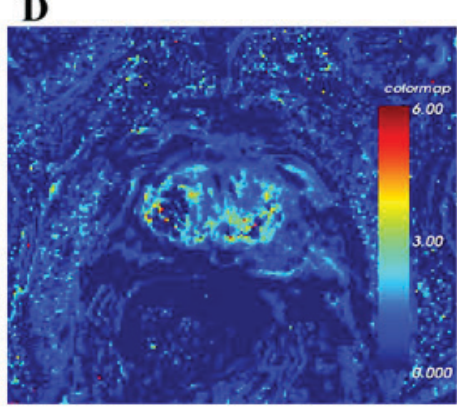

B

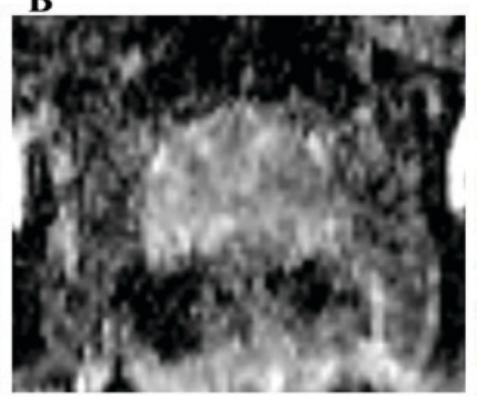

E

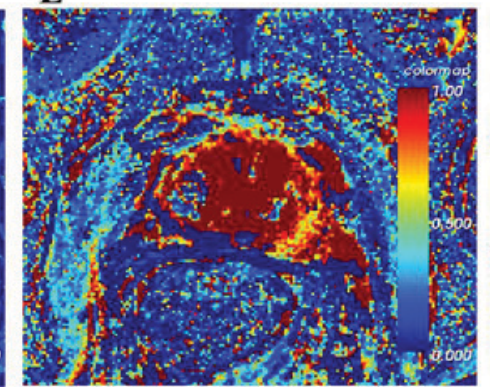

C

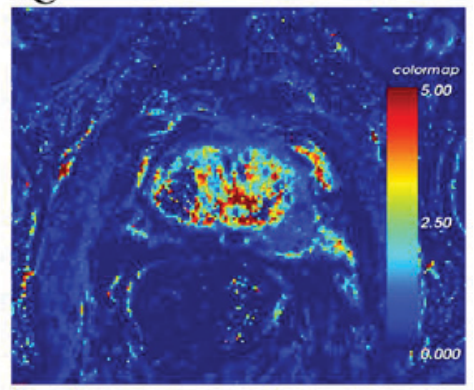

$\mathbf{F}$

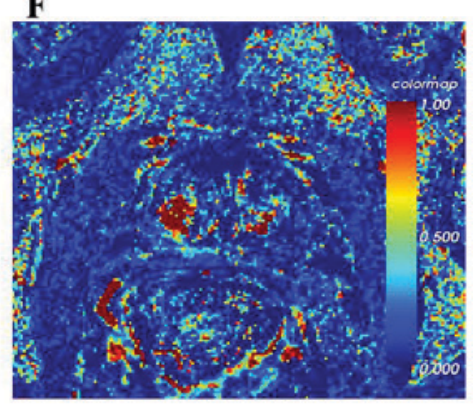

Figure 2. A 74-year-old patient with benign prostatic hyperplasia and repeated dysuria for 2 years (prostate-specific antigen=13.753 ng/ml). (A) T2 weighted image showed slightly higher signal nodules in the right transitional zone (arrow). (B) ADC map showed a high signal with an $\mathrm{ADC}$ value of $2.061 \mathrm{x} 10^{-3} \mathrm{~mm} / \mathrm{s}$. Pseudo-color maps of volume (C) transfer rate constant, (D) back flow rate constant, (E) extravascular extracellular space volume fraction and (F) plasma volume fraction showed values of $1.084 \mathrm{~min}^{-1}, 1.425 \mathrm{~min}^{-1}, 0.636$ and 0.637 , respectively.

may have diagnostic value for $\mathrm{PCa}$; however, its application value and optimal sequence combinations require further investigation.

In the DWI scans of 88 patients with PCa, Nagel et al (15) demonstrated that the ADC values between patients with prostatitis and PCa are significantly different. This finding suggested that DWI may possess high value for the noninvasive diagnosis of PCa. In 117 patients diagnosed with low risk PCa and examined with DWI (Gleason score $\leq 6)(16)$, the ROC curve analysis revealed that the sensitivity and specificity of ADC for PCa are 76.5 and $81 \%$, respectively. The cut-off value of ADC was revealed to be $1.04 \times 10^{-3} \mathrm{~mm}^{2} / \mathrm{sec}$. In another study, a comparison between MRI and pathological results in 201 patients with PCa revealed that T2WI combined with 
Table I. Comparison of vascular permeability parameters and ADC values between the two groups.

\begin{tabular}{lcccccc}
\hline Group & $\mathrm{n}$ & $\mathrm{K}^{\text {trans }}\left(\mathrm{min}^{-1}\right)$ & $\mathrm{K}_{\mathrm{ep}}\left(\mathrm{min}^{-1}\right)$ & $\mathrm{V}_{\mathrm{e}}$ & $\mathrm{V}_{\mathrm{p}}$ & $\mathrm{ADC}\left(\mathrm{x} 10^{-3} \mathrm{~mm}^{2} / \mathrm{sec}\right)$ \\
\hline PCa & 44 & $2.40 \pm 1.13$ & $1.90 \pm 0.72$ & $0.82 \pm 0.24$ & $0.31 \pm 0.25$ & $0.93 \pm 0.43$ \\
BPH & 37 & $1.07 \pm 1.08$ & $1.04 \pm 0.48$ & $0.64 \pm 0.37$ & $0.43 \pm 0.36$ & $1.74 \pm 0.38$ \\
t-value & - & 5.40 & 6.24 & 2.73 & -1.66 & -9.07 \\
P-value & - & $<0.001$ & $<0.001$ & 0.008 & 0.101 & $<0.001$
\end{tabular}

ADC, apparent diffusion coefficient; $\mathrm{BPH}$, benign prostatic hyperplasia; $\mathrm{K}^{\text {trans }}$, volume transfer rate constant; $\mathrm{K}_{\mathrm{ep}}$, back flow rate constant; PCa, prostate cancer; $\mathrm{V}_{\mathrm{e}}$, extravascular extracellular space volume fraction; $\mathrm{V}_{\mathrm{p}}$, plasma volume fraction.

Table II. Efficacy analysis of $\mathrm{K}^{\text {trans }}, \mathrm{K}_{\mathrm{ep}}, \mathrm{V}_{\mathrm{e}}, \mathrm{V}_{\mathrm{p}}$ and ADC values as vascular permeability parameters in the diagnosis of prostate cancer.

\begin{tabular}{lcccccr}
\hline Parameter & AUC & $95 \% \mathrm{CI}$ & $\begin{array}{c}\text { Maximum } \\
\text { Youden index }\end{array}$ & $\begin{array}{c}\text { Sensitivity (\%) } \\
\text { Specificity (\%) }\end{array}$ & Cut off value & P-value \\
\hline $\mathrm{K}^{\text {trans }}$ & 0.819 & $0.718-0.896$ & 0.598 & 84.1 & 75.7 & 1.153 \\
$\mathrm{~K}_{\mathrm{ep}}$ & 0.831 & $0.732-0.905$ & 0.547 & 68.2 & 86.5 & $<0.001$ \\
$\mathrm{~V}_{\mathrm{e}}$ & 0.703 & $0.591-0.799$ & 0.498 & 79.5 & 70.3 & 0.771 \\
$\mathrm{~V}_{\mathrm{p}}$ & 0.581 & $0.466-0.690$ & 0.211 & 32.4 & 88.6 & 0.627 \\
$\mathrm{ADC}$ & 0.914 & $0.831-0.965$ & 0.706 & 86.5 & 84.1 & 0.002 \\
\hline
\end{tabular}

ADC, apparent diffusion coefficient; AUC, area under the curve; CI, confidence interval; BPH, benign prostatic hyperplasia; $\mathrm{K}^{\text {trans }}$, volume transfer rate constant; $\mathrm{K}_{\mathrm{ep}}$, back flow rate constant; $\mathrm{PCa}$, prostate cancer; $\mathrm{V}_{\mathrm{e}}$, extravascular extracellular space volume fraction; $\mathrm{V}_{\mathrm{p}}$, plasma volume fraction.
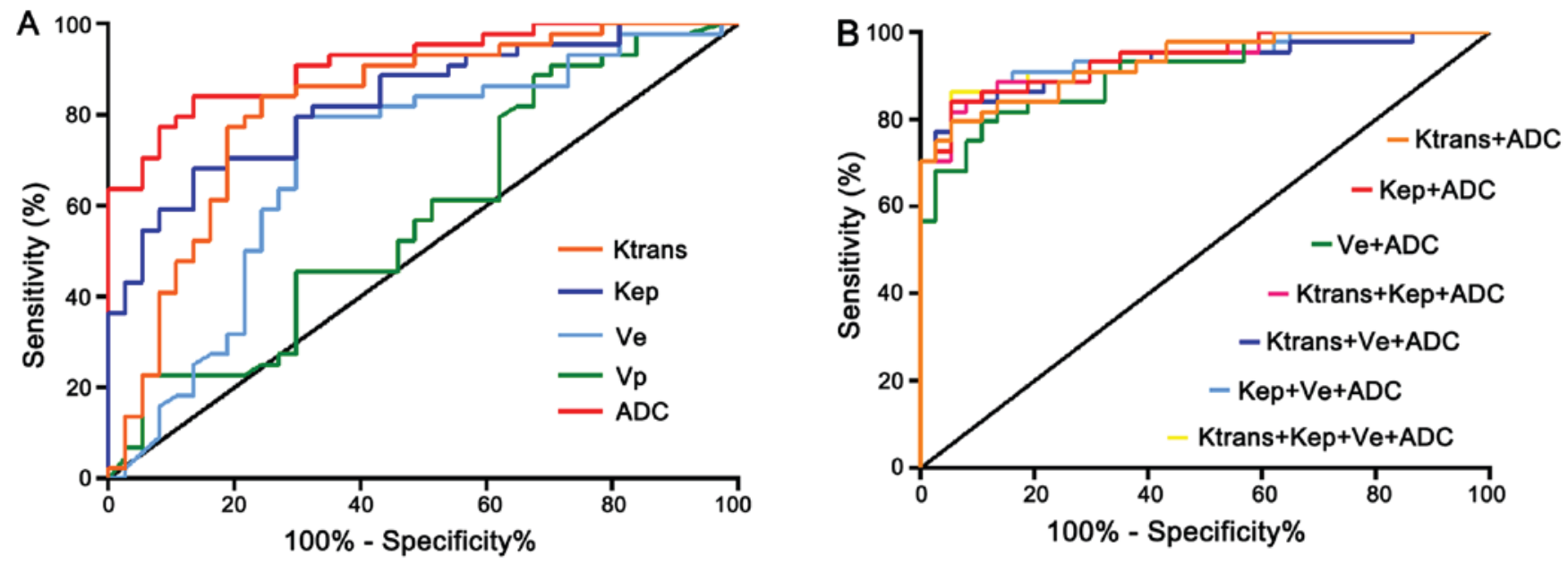

Figure 3. Receiver operating characteristic curve fit of vascular permeability parameters and ADC values of PCa. (A) Single and (B) combined parameters for the diagnosis of PCa were tested. ADC, apparent diffusion coefficient; $\mathrm{PCa}$, prostate cancer; ROC, receiver operating characteristic.

DWI significantly improves the detection rate of PCa (17); the sensitivity, specificity and AUC were $73.2,89.7$ and $0.842 \%$, respectively. These promising results reinforce the use of T2WI combined with DWI as a routine sequence in clinical diagnostic screening of PCa. The present study revealed that the sensitivity and specificity of ADC in diagnosing PCa were 86.5 and $84.1 \%$, respectively, suggesting a high diagnostic efficiency.

PCa can manifest in different ways on MRI images, and each imaging method has its pros and cons. Therefore, a single method for PCa diagnosis is often not sufficient. Multi-parameter imaging, examining differences in anatomy, metabolism and other characteristics of the prostate have garnered much interest in the diagnosis of PCa. Iwazawa et al (18) revealed that DCE-MRI combined with DWI is better than DCE-MRI alone with regards to diagnostic accuracy of $\mathrm{PCa}$ in patients with elevated serum PSA, thus suggesting that DWI provides a high sensitivity and accuracy. Multi-parameter MRI scanning of 55 patients with $\mathrm{PCa}$ demonstrated that $\mathrm{K}^{\text {trans }}$ of DCE-MRI combined with ADC values of DWI imaging offers diagnostic 
Table III. Efficacy analysis of ADC combined with vascular permeability parameters in the diagnosis of prostate cancer.

\begin{tabular}{lccccrr}
\hline Combined parameters & AUC & $95 \% \mathrm{CI}$ & $\begin{array}{c}\text { Maximum Youden } \\
\text { index }\end{array}$ & Sensitivity (\%) & Specificity (\%) & P-value \\
\hline $\mathrm{K}^{\text {trans }}+\mathrm{ADC}$ & 0.931 & $0.880-0.982$ & 0.741 & 94.6 & 79.5 & $<0.001$ \\
$\mathrm{~K}_{\mathrm{ep}}+\mathrm{ADC}$ & 0.939 & $0.891-0.988$ & 0.787 & 94.6 & 84.1 & $<0.001$ \\
$\mathrm{~V}_{\mathrm{e}}+\mathrm{ADC}$ & 0.910 & $0.849-0.970$ & 0.687 & 89.2 & 79.5 & $<0.001$ \\
$\mathrm{~K}^{\text {trans }}+\mathrm{K}_{\mathrm{ep}}+\mathrm{ADC}$ & 0.938 & $0.889-0.987$ & 0.764 & 94.6 & 81.8 & $<0.001$ \\
$\mathrm{~K}^{\text {trans }}+\mathrm{V}_{\mathrm{e}}+\mathrm{ADC}$ & 0.929 & $0.872-0.986$ & 0.787 & 94.6 & 84.1 & $<0.001$ \\
$\mathrm{~K}_{\mathrm{ep}}+\mathrm{V}_{\mathrm{e}}+\mathrm{ADC}$ & 0.939 & $0.889-0.989$ & 0.787 & 94.6 & 84.1 & $<0.001$ \\
$\mathrm{~K}^{\text {trans }}+\mathrm{K}_{\mathrm{ep}}+\mathrm{V}_{\mathrm{e}}+\mathrm{ADC}$ & 0.940 & $0.890-0.990$ & 0.810 & 94.6 & 86.4 & $<0.001$ \\
\hline
\end{tabular}

ADC, apparent diffusion coefficient; BPH, benign prostatic hyperplasia; AUC, area under the curve; CI, confidence interval; $\mathrm{K}^{\text {trans }}$, volume transfer rate constant; $\mathrm{K}_{\mathrm{ep}}$, back flow rate constant; PCa, prostate cancer; $\mathrm{V}_{\mathrm{e}}$, extravascular extracellular space volume fraction; $\mathrm{V}_{\mathrm{p}}$, plasma volume fraction.

Table IV. Correlation analysis between vascular permeability parameters and ADC values in prostate cancer, and Gleason score.

\begin{tabular}{|c|c|c|c|c|c|c|c|c|c|c|}
\hline \multirow[b]{2}{*}{ Variable } & \multicolumn{2}{|c|}{$\mathrm{K}^{\text {trans }}$} & \multicolumn{2}{|c|}{$\mathrm{K}_{\mathrm{ep}}$} & \multicolumn{2}{|c|}{$\mathrm{V}_{\mathrm{e}}$} & \multicolumn{2}{|c|}{$\mathrm{V}_{\mathrm{p}}$} & \multicolumn{2}{|c|}{$\mathrm{ADC}$} \\
\hline & $\mathrm{r}$ & P-value & $\mathrm{r}$ & P-value & $\mathrm{r}$ & P-value & $\mathrm{r}$ & P-value & $\mathrm{r}$ & P-value \\
\hline $\begin{array}{l}\text { Primary Gleason } \\
\text { pattern }\end{array}$ & -0.151 & 0.329 & 0.082 & 0.596 & -0.025 & 0.871 & -0.385 & 0.010 & -0.665 & $<0.001$ \\
\hline $\begin{array}{l}\text { Secondary Gleason } \\
\text { pattern }\end{array}$ & -0.246 & 0.107 & -0.295 & 0.052 & -0.198 & 0.199 & -0.017 & 0.120 & -0.456 & $<0.001$ \\
\hline Total Gleason score & -0.249 & 0.104 & -0.126 & 0.415 & -0.149 & 0.334 & -0.237 & 0.122 & -0.714 & $<0.001$ \\
\hline
\end{tabular}

$\mathrm{ADC}$, apparent diffusion coefficient; $\mathrm{K}^{\text {trans }}$, volume transfer rate constant; $\mathrm{K}_{\mathrm{ep}}$, back flow rate constant; PCa, prostate cancer; $\mathrm{V}_{\mathrm{e}}$, extravascular extracellular space volume fraction; $\mathrm{V}_{\mathrm{p}}$, plasma volume fraction.

sensitivity, specificity, accuracy and AUC of 71, 86 and $78 \%$, and 0.79 , respectively (19). Compared with the combinations of any other two modalities of MRI, including T2WI+DWI, T2WI+DCE, T2WI+MRS, DWI+MRS and DCE+MRS, DCE-MRI combined with DWI has the best diagnostic efficiency for the diagnosis of $\mathrm{PCa}$ (19). The present study analyzed the efficiency of ADC combined with vascular permeability parameters in the diagnosis of $\mathrm{PCa}$. The results revealed that the diagnostic sensitivity and specificity of $\mathrm{K}^{\text {trans }}+\mathrm{K}_{\mathrm{ep}}+\mathrm{V}_{\mathrm{e}}+$ ADC was higher than that of single parameters. Notably, the diagnostic efficiency of $\mathrm{K}_{\mathrm{ep}}+\mathrm{ADC}(\mathrm{AUC}=0.939)$ was similar to that of the four combined (AUC $=0.940$, thus suggesting that $\mathrm{K}_{\mathrm{ep}}$ and ADC may be used as the main parameters for DCE-MRI combined with DWI for the diagnosis of PCa.

The Gleason classification is a commonly used method in histological grading of $\mathrm{PCa}$, due to its association with biological parameters and prognosis of $\mathrm{PCa}$; therefore, it has become an important reference index for the treatment of $\mathrm{PCa}(8,9)$. The growth and invasion of PCa depends on the degree of tumor angiogenesis. Prognosis is therefore closely associated with the amount of angiogenesis (20-22), and PCa is characterized by low degrees of differentiation. In addition, tumor growth is associated with recruitment of new vasculature, which is naturally leaky compared with healthy vasculature. Bigler et al (23) revealed that the mean microvascular density of PCa was associated with the Gleason score, tumor staging and prognosis. In particular, elevated $\mathrm{K}^{\text {trans }}$ values are associated with an increase in the Gleason score. These results suggested that the $\mathrm{K}^{\text {trans }}$ value may be used to predict the degree of malignancy and overall prognosis. However, in previous studies, DCE-MRI performed in patients with $\mathrm{PCa}$ revealed that $\mathrm{K}^{\text {trans }}, \mathrm{K}_{\mathrm{ep}}$ and $\mathrm{V}_{\mathrm{e}}$ values are not correlated with the Gleason score $(11,24)$, in agreement with other research $(25)$. In addition, a low negative correlation was observed between $\mathrm{V}_{\mathrm{p}}$ and primary Gleason pattern of $\mathrm{PCa}(\mathrm{r}=-0.385, \mathrm{P}<0.05)$. No significant correlation between $\mathrm{V}_{\mathrm{p}}$ and the secondary Gleason pattern or total Gleason score was found. There was no correlation between $V_{p}$ and the Gleason score, which may be due to the intravascular contrast agent, the distribution of which is closely associated with the density and wall permeability of tumor angiogenesis. An increase in $\mathrm{V}_{\mathrm{p}}$ may be initiated by increased retention of contrast agent in the blood vessels in patients with $\mathrm{PCa}$. As the malignancy of PCa increases, blood vessel permeability also increases; therefore, the amount of contrast agent in the vasculature is decreased. This represents how $V_{p}$ may be associated with the grading of $\mathrm{PCa}$, allowing it to be used to evaluate the degree of malignancy and prognosis of $\mathrm{PCa}$. However, optimal measurement methods or software have yet to be established for $\mathrm{V}_{\mathrm{e}}$ and $\mathrm{V}_{\mathrm{p}}$, and the accuracy of quantitative analysis requires further investigation. This study 
also revealed that ADC values were lower in PCa tissue than in BPH tissue. Hambrock et al performed DWI in 51 patients with $\mathrm{PCa}$ (26). The results revealed that the ADC value of patients with $\mathrm{PCa}$ is negatively correlated with the Gleason score. An increase of 1 level in the Gleason grade is observed in combination with each decrease in the ADC value of $(0.18 \pm 0.02) \times 10^{-3} \mathrm{~mm}^{2} / \mathrm{sec}$. In the present study, the ADC value in the PCa area was negatively correlated with primary and secondary Gleason patterns of tumor grading and the Gleason total score, which suggested rapid proliferation of tumor cells in cancerous lesions, resulting in close arrangement of abnormal tumor cells, compression and deformation of the extracellular space and restriction of water molecule diffusion. This may lead to a decrease in water content and motility, inducing a decrease in ADC. This suggested that ADC value may be used to assess the invasion and recurrence of tumors, and may serve as a reference tool for clinical treatment plans.

The present study however presents some limitations: i) The use of contrast agents in DCE-MRI may increase the risk of adverse reactions; ii) there may be deviations in the measured value and the results from puncture biopsy under ultrasound in 29 patients; iii) ROIs were placed in the largest cross-section of the lesion with simple operation and good repeatability, but other aspects of the lesion tissue that may affect the precise measurement of the value were not considered; and iv) based on Gauss diffusion theory, DWI can noninvasively detect the diffusion of water molecules in living tissues. The DWI signal is known to represent a single exponential function with attenuation and increasing B value. However, to a certain extent, the diffusion of water molecules in biological tissues is more complex than free water and the shift of water molecules in tissues differs from Gaussian distributions. These deviations are in contradiction with the single exponential model and are affected by the cell membrane, and inner and outer septal diffusion barrier. These factors may alter the detection rate of $\mathrm{PCa}$. A double exponential model of intravoxel incoherent motion imaging, which allows a more comprehensive analysis of data of DWI, and diffusional kurtosis imaging of Taylor expansion, which provides quantifiable information on the non-Gaussian behavior of water diffusion in biological tissue and reveals subtle substructural changes, could be considered in the future to study the diagnostic value of benign and malignant prostate lesions, in order to improve the detection rate and diagnostic efficiency of $\mathrm{PCa}$.

In conclusion, DCE-MRI combined with quantitative analysis of DWI may improve the diagnostic efficacy of $\mathrm{PCa}$, and provide differential diagnoses between benign and malignant prostate lesions. The methods proposed herein may aid the determination of invasion and prognosis of tumors in a non-invasive manner, and provide a real and systematic imaging basis for clinical practice.

\section{Acknowledgements}

Not applicable.

\section{Funding}

The study was supported by the Medical and Health Science and Technology Project (grant nos. 2014KYB171 and 2018KY555), and the Chinese Medicine Science and Technology Project (grant no. 2014ZB042), Zhejiang Province.

\section{Availability of data and materials}

The datasets used and/or analyzed during the current study are available from the corresponding author on reasonable request.

\section{Authors' contributions}

All authors contributed to this paper. SWW and XZM designed the outline for the study; XZM and KL acquired the experimental data, and searched and read the related literature, and XZM wrote the paper; PPP and JLS offered assistance for data acquisition; MSX and YXY as senior radiologists evaluated the images and provided great assistance in the analysis and interpretation of data in the experiment; SWW, XZM, KL and JLS revised and edited the paper; and all authors approved the final version.

\section{Ethics approval and consent to participate}

The institutional review board approved this retrospective study and waived informed consent.

\section{Patient consent for publication}

Not applicable.

\section{Competing interests}

The authors declare that they have no competing interests.

\section{References}

1. Decelle EA and Cheng LL: High-resolution magic angle spinning 1H MRS in prostate cancer. NMR Biomed 27: 90-99, 2014.

2. Chen W, Zheng R, Baade PD, Zhang S, Zeng H, Bray F, Jemal A, Yu XQ and He J: Cancer statistics in China, 2015. CA Cancer J Clin 66: 115-132, 2016.

3. Hoeks CM, Barentsz JO, Hambrock T, Yakar D, Somford DM, Heijmink SW, Scheenen TW, Vos PC, Huisman $H$ van Oort IM, et al: Prostate cancer: Multiparametric MR imaging for detection, localization, and staging. Radiology 261: 46-66, 2011.

4. Rosenkrantz AB, Sabach A, Babb JS, Matza BW, Taneja SS and Deng FM: Prostate cancer: Comparison of dynamic contrast-enhanced MRI techniques for localization of peripheral zone tumor. AJR Am J Roentgenol 201: W471-W478, 2013.

5. Manenti G, Squillaci E, Di Roma M, Carlani M, Mancino S and Simonetti G: In vivo measurement of the apparent diffusion coefficient in normal and malignant prostatic tissue using thin-slice echo-planar imaging. Radiol Med 111: 1124-1133, 2006 (In English, Italian).

6. Malayeri AA, El Khouli RH, Zaheer A, Jacobs MA, Corona-Villalobos CP, Kamel IR and Macura KJ: Principles and applications of diffusion-weighted imaging in cancer detection, staging, and treatment follow-up. Radiographics 31: 1773-1791, 2011.

7. Petrescu A, Mârzan L, Codreanu O and Niculescu L: Immunohistochemical detection of $\mathrm{p} 53$ protein as a prognostic indicator in prostate carcinoma. Rom J Morphol Embryol 47: 143-146, 2006.

8. Gleason DF and Mellinger GT: Prediction of prognosis for prostatic adenocarcinoma by combined histological grading and clinical staging. J Urol 167: 58-64, 1974.

9. Stark JR, Perner S, Stampfer MJ, Sinnott JA, Finn S, Eisenstein AS, Ma J, Fiorentino M, Kurth T, Loda M, et al: Gleason score and lethal prostate cancer: Does $3+4=4+3$ ? J Clin Oncol 27: 3459-3464, 2009.

10. Sourbron SP and Buckley DL: On the scope and interpretation of the Tofts models for DCE-MRI. Magn Reson Med 66: 735-745, 2011. 
11. Schlemmer HP, Merkle J, Grobholz R, Jaeger T, Michel MS, Werner A, Rabe J and van Kaick G: Can pre-operative contrast-enhanced dynamic MR imaging for prostate cancer predict microvessel density in prostatectomy specimens? Eur Radiol 14: 309-317, 2004.

12. Kozlowski P, Chang SD, Jones EC, Berean KW, Chen H and Goldenberg SL: Combined diffusion-weighted and dynamic contrast-enhanced MRI for prostate cancer diagnosis-correlation with biopsy and histopathology. J Magn Reson Imaging 24: 108-113, 2006

13. Baur AD, Maxeiner A, Franiel T, Kilic E, Huppertz A, Schwenke C, Hamm B and Durmus T: Evaluation of the prostate imaging reporting and data system for the detection of prostate cancer by the results of targeted biopsy of the prostate. Invest Radiol 49: 411-420, 2014.

14. Hoeks CM, Hambrock T, Yakar D, Hulsbergen-van de Kaa CA, Feuth T, Witjes JA, Fütterer JJ and Barentsz JO: Transition zone prostate cancer: Detection and localization with 3-T multiparametric MR imaging. Radiology 266: 207-217, 2013.

15. Nagel KN, Schouten MG, Hambrock T, Litjens GJ, Hoeks CM, ten Haken B, Barentsz JO and Fütterer JJ: Differentiation of prostatitis and prostate cancer by using diffusion-weighted MR imaging and MR-guided biopsy at 3 T. Radiology 267: 164-172, 2013.

16. Itatani R, Namimoto $T$, Kajihara H, Katahira K, Kitani K, Hamada Y and Yamashita Y: Triage of low-risk prostate cancer patients with PSA levels $10 \mathrm{ng} / \mathrm{ml}$ or less: Comparison of apparent diffusion coefficient value and transrectal ultrasound-guided target biopsy. Am J Roentgenol 202: 1051-1057, 2014.

17. Katahira K, Takahara T, Kwee TC, Oda S, Suzuki Y, Morishita S, Kitani K, Hamada Y, Kitaoka M and Yamashita Y: Ultra-high-b-value diffusion-weighted MR imaging for the detection of prostate cancer: Evaluation in 201 cases with histopathological correlation. Eur Radiol 21: 188-196, 2011.

18. Iwazawa J, Mitani T, Sassa S and Ohue S: Prostate cancer detection with MRI: Is dynamic contrast-enhanced imaging necessary in addition to diffusion-weighted imaging? Diagn Interv Radiol 17: 243-248, 2011.
19. Jambor I, Kähkönen E, Taimen P, Merisaari H, Saunavaara J, Alanen K, Obsitnik B, Minn H, Lehotska V and Aronen HJ: Prebiopsy multiparametric 3T prostate MRI in patients with elevated PSA, normal digital rectal examination, and no previous biopsy. J Magn Reson Imaging 41: 1394-1404, 2015.

20. Epstein JI, Allsbrook WC Jr, Amin MB and Egevad LL; ISUP Grading Committee: The 2005 international society of urological pathology (ISUP) consensus conference on Gleason grading of prostatic carcinoma. Am J Surg Pathol 29: 1228-1242, 2005.

21. Buhmeida A, Pyrhönen S, Laato M and Collan Y: Prognostic factors in prostate cancer. Diagn Pathol 1: 4, 2006.

22. Harnden P, Shelley MD, Coles B, Staffurth J and Mason MD: Should the Gleason grading system for prostate cancer be modified to account for high-grade tertiary components? A systematic review and meta-analysis. Lancet Oncol 8: 411-419, 2007.

23. Bigler SA, Deering RE and Brawer MK: Comparison of microscopic vascularity in benign and malignant prostate tissue. Hum Pathol 24: 220-226, 1993.

24. Padhani AR, Gapinski CJ, Macvicar DA, Parker GJ, Suckling J, Revell PB, Leach MO, Dearnaley DP and Husband JE: Dynamic contrast enhanced MRI of prostate cancer: Correlation with morphology and tumour stage, histological grade and PSA. Clin Radiol 55: 99-109, 2000.

25. Chen YJ, Chu WC, Pu YS, Chueh SC, Shun CT and Tseng WY: Washout gradient in dynamic contrast-enhanced MRI is associated with tumor aggressiveness of prostate cancer. J Magn Reson Imaging 36: 912-919, 2012.

26. Hambrock T, Somford DM, Huisman HJ, van Oort IM, Witjes JA, Hulsbergen-van de Kaa CA, Scheenen T and Barentsz JO: Relationship between apparent diffusion coefficients at 3.0-T MR imaging and Gleason grade in peripheral zone prostate cancer. Radiology 259: 453-461, 2011.

(i) (5) This work is licensed under a Creative Commons Attribution-NonCommercial-NoDerivatives 4.0 International (CC BY-NC-ND 4.0) License. 